\title{
FUTURE MATERIALS
}

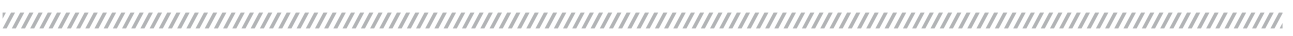

\section{Dear Readers,}

Of the many challenges that the automotive industry face - increasing global competition, improved vehicle performance that deliver higher efficiency, cost reduction and tighter environmental and safety requirements - the biggest headache comes from the pressure it receives from governments and the global community to cut down on $\mathrm{CO}_{2}$ emissions. And materials play a very vital role in overcoming these challenges.

A study by Market Realist in 2015 noted that raw materials contribute about $47 \%$ to the cost of a vehicle. Of this, an average automobile has approximately $47 \%$ steel, $8 \%$ iron and plastic each, 7 $\%$ aluminium, $3 \%$ glass, while other materials account for the remaining $27 \%$. Over the years, the content of aluminium and advanced high strength steel in vehicles is increasing, thanks largely to the stringent fuel economy standards that nations are adopting. OEMs are also adopting composites due to their strength, quality and lighter weight.

The use of magnesium in the Indian automotive industry at present is very low, but engineers and researchers have harped strongly on the huge potential it has got for automotive applications. In one of our previous Technology Foresight articles, researchers at TIFAC spoke about the potential to use magnesium thin-walled die-castings to lightweight transmission components, engine cradle, seat frames, instrument panels and steering wheels. The industry globally has taken a collective target to use an average of $159 \mathrm{~kg}$ of magnesium components in vehicles by 2020, and that should significantly lower the weight of an average car.

An interesting new trend is that of bio-based polymers and natural fibres. Bio-based alternatives derived from renewable raw materials such as wood, cotton, jute, flax or coir are finding growing acceptance among manufacturers and suppliers. Even in the Indian context, we have had examples of OEMs offering door trims and roof-liners made of jute. Although the use of bio-based materials is still in its infancy, its adoption for sure is on a gradual increase in the auto industry.

Despite the adoption of advanced lightweight materials gaining momentum, there is tremendous amount of deliberations still undergoing in corporate boardrooms on what is right for the future. There is no deniability that future materials for vehicles have to be light, efficient, recyclable, biobased and possibly bio-degradable. And all of these would still need to ensure future vehicle delivers on performance, environment and safety.

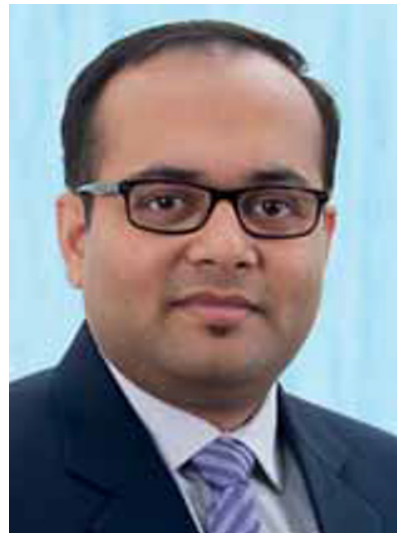

autotechreview.com 